\title{
Teorias praxiológicas da percepção e a concentricidade entre espaço, corpo próprio e intersubjetividade
}

\section{Praxiological theories of perception and the concentricity of space, own body and intersubjectivity}

\author{
Danilo Saretta Verissimo \\ Universidade Estadual Paulista Júlio Mesquita - Campus Assis \\ Departamento de Psicologia Social \\ Brasil
}

\begin{abstract}
Resumo
Circunscrevemos e examinamos, neste trabalho de cunho teórico, linhas de estudo, redes conceituais e discussões em torno da percepção que se destaquem no âmbito do que denominamos de teorias praxiológicas da intencionalidade perceptiva. Orientamo-nos, em termos teóricometodológicos, pela tradição fenomenológica. Partimos do pressuposto, presente nas abordagens fenomenológicas da percepção, da concentricidade entre a experiência perceptiva do espaço, do corpo próprio e de outrem. Combinados a estes três eixos concêntricos, elencamos, para a discussão, os problemas da atenção perceptual e da percepção amodal, do esquema e da imagem corporal, e da atenção conjunta e dos neurônios espelho. São reforçados, na análise, os vínculos entre percepção e ação, o que nos aproxima de uma concepção corpórea e situada da subjetividade.
\end{abstract}

Palavras-chave: percepção; espaço; corpo; intersubjetividade; fenomenologia.

\begin{abstract}
We circumscribe and examine, in this theoretical paper, lines of study, conceptual networks and discussions about perception that stand out in the scope of what we call praxiological theories of perceptual intentionality. We are guided, in theoretical and methodological terms, by the phenomenological tradition. We start from the assumption, present in the phenomenological approaches of perception, of the concentricity among the perceptual experience of space, of the own body and of others. Combined with these three concentric axes, we listed, for discussion, the problems of perceptual attention and amodal perception, scheme and body image, and joint attention and mirror neurons. In the analysis, the bonds between perception and action are reinforced, which brings us closer to an embodied and situated conception of subjectivity.
\end{abstract}

Keywords: perception; space; body; intersubjectivity; phenomenology.

\section{Introdução}

Ao lado de uma posição epistemológica dos problemas relativos à percepção que predominou durante muito tempo, é possível reconhecer uma concepção que 
identifica a percepção com a ação situada, ou seja, integrada ao mundo, e, principalmente, "como modalidade originária da relação de um vivente com o seu meio" (Barbaras, 2006, p.IX, tradução nossa). A percepção, nestes termos, consiste numa atividade, apenas compreensível sob "o fundo de um movimento e de um esforço vital" (Sévérac, 2004, p.34, tradução nossa). Enfatiza-se, nessa via, o binômio percepção e ação, especialmente as capacidades motrizes do sujeito perceptivo. Essa disposição filosófica para considerar a percepção como "modo de exploração e de elaboração do mundo" (Barbaras, 2006, p.X, tradução nossa) encontrou espaço, simultaneamente, na biologia e na psicologia científica do século XX. À luz da descrição das modalidades perceptivas encontradas na escala dos viventes, vê-se que o "objeto" da percepção não é exatamente um objeto, mas movências, formas, distâncias espaciais e escoamentos temporais. Impossível destacar, ademais, os processos perceptivos da atividade vital que eles denotam, especialmente do contexto qualitativo e afetivo que integram.

Nosso propósito, neste artigo, é aproximarmo-nos de questões relativas à consciência perceptiva a partir da análise de aportes conceituais e experimentais contemporâneos provindos da psicologia, das neurociências cognitivas, da filosofia da mente e da fenomenologia. Malgrado as diferenças que existem no seu interior, esses aportes possuem convergências. Delimitamos, em meio desses distintos campos do saber, um espaço conceitual fundamentado, justamente, numa concepção corpórea da subjetividade, e que se pauta em um tipo de intencionalidade motora, compatível com a posição do sentido prático e vital da percepção. Nosso objetivo específico é, nesse contexto, circunscrever e examinar, ainda que de forma introdutória, linhas de estudo, redes conceituais e discussões em torno da percepção que se destaquem no âmbito do que se poderia chamar, com Bimbenet (2015), de "teorias praxiológicas da intencionalidade" (p.70, tradução nossa). Orientamo-nos, em termos teóricometodológicos, pela tradição filosófica fenomenológica. Nossa investigação baseia-se no pressuposto, presente nas abordagens fenomenológicas da percepção, de que o exame circunstanciado das potencialidades e dos limites dessas teorias exige a apreciação não apenas de pontos relativos à integração perceptiva do espaço, mas, igualmente, de problemas concernentes à percepção do corpo próprio e à intersubjetividade. Admitimos, portanto, uma concentricidade entre os planos da experiência do espaço, do corpo próprio e de outrem. A consideração da relação entre o espaço corporal e o campo percebido, bem como o fato de que este campo é partilhado, abre, ademais, vias produtivas de interrogação da intencionalidade motora, notadamente a que possibilita 
pensar a questão da objetividade da percepção a partir dos limites da motricidade.

Nossa argumentação é orientada segundo os três eixos concêntricos supracitados. Caracterizamos, primeiramente, um paradigma sensório-motor da percepção e sua ligação à questão da integração do espaço percebido. Destacamos, nesse ponto, duas linhas de investigação: a questão da atenção perceptiva e a do caráter amodal da percepção. Nosso segundo tópico é o problema da percepção do corpo próprio e sua relação com a integração do espaço. Salientamos, nesse plano, pesquisas e discussões sobre os conceitos de esquema corporal e de imagem corporal. Discorremos, por fim, sobre o domínio de ação da estrutura intencional da percepção no âmbito da intersubjetividade, ressaltando pesquisas sobre a atenção conjunta e os neurônios espelho. Cada um desses conceitos e dessas linhas de pesquisa sobressai na literatura filosófica e científica sobre a percepção em virtude do seu vínculo, no âmbito teórico, à matriz praxiológica da intencionalidade perceptiva.

\section{A integração ativa do espaço percebido}

Mesmo um gênero ortodoxo de posição acerca da percepção, e que reforça a ideia de um sujeito extramundano, seja na qualidade de receptáculo de sensações, seja como fonte intelectual de inferência das qualidades do mundo a partir das estimulações que advêm dele, admite a dependência entre percepção e ação. Neste caso, contudo, esta ligação é estabelecida em termos meramente instrumentais. Na medida em que alteram a nossa relação espacial com os objetos, os movimentos corporais devem modificar nossas condições de aquisição de informação perceptiva. Movemos nosso dorso, e vemos novas propriedades das coisas. Manuseamos objetos e obtemos informações sobre a sua forma, sua temperatura e sua textura. Movendo-nos, podemos, também, nos proteger de estímulos aversivos, sejam eles visuais, olfativos etc. Fato é que, na concepção instrumental, as alterações motoras figuram apenas como ocasiões para mudanças na recepção perceptiva, ou nos chamados inputs sensoriais (Briscoe \& Grusch, 2015).

Em outras teorias, essa dependência entre percepção e ação é estabelecida em termos constitutivos. A tradição fenomenológica é um bom exemplo dessa categoria. Husserl (1973/1989) dá destaque à ação e à corporalidade no estudo da percepção. Toda percepção, afirma o autor, tem o corpo como termo subentendido e que participa da sua determinação de tal e tal maneira. Esta é, segundo o filósofo, a dimensão propriamente subjetiva da percepção. O autor 
estabelece, nesse sentido, uma relação de co-pertença entre as sensações visuais e táteis, e as sensações cinestésicas. Estas últimas tornam possível a exposição dos objetos e do espaço, sem que elas mesmas exponham algo. Cada posição do corpo determina certas imagens perceptivas. As coisas percebidas, por sua vez, jamais se expõem completamente, exigindo contínuos esforços de movimentação corporal em busca da complementação da doação perceptiva. Merleau-Ponty (1945) desenvolve esses preceitos. De acordo com o autor, a percepção de objetos no espaço reclama a ideia de campo perceptivo, posto que a manifestação perceptiva de um objeto, além de se furtar à sua exposição completa, implica o encobrimento de outros objetos. O recuo do horizonte perceptivo e das partes ocultas de um objeto denota o caráter situado da percepção, além de evidenciar a dimensão de ausência que caracteriza a experiência perceptiva, e motiva o movimento do sujeito percipiente. Eis dois elementos básicos que se interpenetram em uma filosofia fenomenológica da percepção: a potência motora do sujeito percipiente e a transcendência da coisa percebida.

É significativa a convergência entre a tradição fenomenológica e as abordagens da percepção, em ciências cognitivas, orientadas para ação, embora se deva destacar, igualmente, a variedade de influências e de configurações que os diversos programas de pesquisa em ciências cognitivas e em filosofia adotam em torno do binômio percepção-ação. O ponto comum é justamente este: "a insistência na inseparabilidade entre a percepção e ação" (Nöe \& Thompson, 2002, p.3, tradução nossa), o que configura um paradigma sensório-motor da percepção. As pesquisas passíveis de ser abrigadas sob a alcunha de um paradigma sensório-motor da percepção afirmam o caráter enativo da percepção, quer dizer, a relação intrínseca entre nossos mais variados movimentos e suas consequências sensoriais. Atesta-se, pois, uma espécie de saber sensório-motor (Varela, Thompson \& Rosch, 1993; Bimbenet, 2015). Alguns dos principais problemas concernentes às relações entre a organização perceptiva e a atividade motora revelam-se em investigações acerca da atenção perceptiva e do caráter amodal da percepção, pontos aos quais nos dedicamos a seguir.

Noë e O'Regan (2002) distinguem a sensibilidade perceptual da consciência perceptual (perceptual awareness). Esta última envolve o uso da informação perceptiva no trato com as circunstâncias ambientais e sociais, ainda que de forma não reflexiva. Um motorista de automóvel normalmente não está ciente de todas as contingências sensório-motoras necessárias para a condução do veículo e, ainda assim, consegue dominá-las. As pessoas, além disso, não experienciam 
todos os detalhes presentes no seu campo visual. Elas possuem determinados focos de atenção. Alguns experimentos referentes à atenção visual, e identificados pelo paradigma da cegueira para mudança (change blindness), revelam a dificuldade de observadores para detectar mudanças em cenas cotidianas apresentadas em imagens e nas quais objetos se movem, aparecem e desaparecem, ou têm as cores pouco a pouco alteradas (Rensink, O'Regan \& Clark, 1997; Simons \& Levin, 1997). Outros estudos, referentes à cegueira inatencional (inattentional blindness), partem do envolvimento dos sujeitos com tarefas experimentais para testar sua capacidade de atentar para estímulos adicionais apresentados em meio a objetos complexos e eventos dinâmicos (Simons \& Chabris, 1999; Mack, 2003). Muitos indivíduos não notam os estímulos externos adicionais. Estes resultados chocam-se com a suposição ordinária de que temos consciência dos detalhes do nosso ambiente, ou com a concepção científica de que o sistema visual elabora uma representação interna detalhada do ambiente tridimensional a partir de sucessivas fixações óticas de uma cena qualquer. Segundo Noë e O'Regan (2002), tem-se formulado um desafio à "a ideia de que todo o detalhe está presente na cabeça agora" (p.577, tradução nossa, grifo no original). Se assim fosse, a cegueira para a mudança não seria possível. Ao contrário, afirmam, "o detalhe está lá" (Noë \& O’Regan, 2002, p.577, tradução nossa, grifo no original), na frente de nós, "no mundo" (p.577, tradução nossa), de modo que a visão do detalhe depende do movimento dos nossos olhos, da cabeça e de outras partes do nosso corpo.

Desconsiderando a versão internalista da percepção, Noë (2004, 2012) desenvolve as questões da cegueira para mudança e da cegueira inatencional numa direção complementar ao fato de que não atentamos a todos os detalhes de uma cena perceptiva. Temos, além disso, o "senso da presença" (Noë, 2004, p.59, tradução nossa) daquilo que não percebemos diretamente. Afirmar que apenas vemos aquilo para o que nos voltamos não dá conta da consciência perceptual referente a aspectos de fundo do campo visual. Ao olharmos atentamente para alguém, temos um senso da presença da parede atrás dela, da cor deste fundo perceptivo e da distância entre ele e a pessoa. É preciso investigar como é possível usufruir a experiência perceptiva das características desapercebidas de uma cena. Para Noë, este é o problema da "presença perceptual" (perceptual presence). Se segurarmos uma garrafa com os olhos fechados, teremos o senso da presença da garrafa inteira. Se observarmos um gato sentado atrás de uma cerca, teremos a experiência perceptiva do animal como um todo, malgrado o fato de apenas contarmos com a exposição das partes do gato visíveis nos interstícios da estacaria. Qualquer objeto, ademais, 
apresenta-se com volume e tridimensionalidade. Se olho para um tomate, desde uma certa perspectiva, tenho a experiência de uma fruta sólida e voluminosa, a despeito de vê-la segundo uma de suas faces.

A partir dos trabalhos de Michotte (1955; Michotte, Thinès \& Grabbé, 1964; Wagemans, Van Lier \& Scholl, 2006; Wagemans e outros, 2012), a ocorrência necessária e, por consequência, cotidiana de se ter acesso apenas à exposição de partes das coisas que nos cercam, sem que a realidade fenomenal deixe de nos dar objetos com formas contínuas e voluminosas, passou a ser chamada de percepção amodal. Dando continuidade a uma psicologia experimental inspirada na Psicologia da Gestalt, os estudos sobre a percepção amodal, ou complemento amodal (complément amodal, no francês, e amodal completion, no inglês) vem sendo realizados, desde Michotte, com base, sobretudo, em padrões bidimensionais em que superfícies planas são apresentadas de maneira que uma delas encontre-se parcialmente encoberta pela outra (Van Lier \& Gerbino, s/d; Wagemans e outros, 2006). Abordagens baseadas em disposições de imagens que se referem a ambientes tridimensionais, centradas em formas voluminosas, também vêm sendo desenvolvidas, como evidencia o trabalho de Tse (1999).

Uma explicação corrente do fenômeno da experiência integral das coisas afirma que recorremos a habilidades conceituais que asseguram, para nós, a totalidade do objeto percebido. Mas não estamos interessados, afirma Noë (2004), em atos de pensamento e de julgamento, nem mesmo de imaginação, e sim no "senso perceptual" (p.60, tradução nossa) da presença das coisas. Estas nos são dadas, perceptivamente, como totalidades. A proposta de Noë é que se compreenda o senso da presença perceptual a partir de um paradigma sensóriomotor. As coisas que nos circundam "estão perceptivamente presentes no sentido de que elas são perceptivamente acessíveis para nós", afirma Noë (2004, p.63, tradução nossa), que, mais adiante, completa:

\begin{abstract}
Meu senso da presença do gato inteiro atrás da cerca consiste, precisamente, no meu conhecimento, meu entendimento implícito, de que, com um movimento do olho, ou da cabeça, ou do corpo, posso trazer à vista partes do gato que agora estão ocultas. Esta é uma das pretensões centrais da abordagem enativa ou sensóriomotora da percepção (p.63-64).
\end{abstract}

De acordo com Noë (2004, 2012), temos, portanto, uma compreensão tácita a respeito da relação entre, por exemplo, a voluminosidade das coisas, que corresponde a um dos seus índices de realidade, ou de presença, e a sua aparência a partir de um certo ponto de vista, variável conforme o nosso movimento. Esta compreensão implícita equivale a um senso prático referente à 
relação entre movimentos corpóreos e mudanças sensórias. Noë (2012) afirma: "Minha ênfase aqui é em um tipo especial de compreensão que subscreve distintivamente nosso acesso perceptivo a objetos e propriedades, nomeadamente, uma compreensão sensório-motora" (p.20, tradução nossa, grifo no original).

Há críticas pertinentes, por parte de fenomenólogos (Kelly, 2008; Bimbenet, 2015), a respeito dessa formulação teórica. Elas não se dirigem à importância da ação na percepção, mas à natureza desse entendimento implícito acerca da relação entre a aparência das coisas, o movimento corpóreo e a presença perceptiva. Noë (2004) sustenta uma "dualidade de conteúdos" (p.163, tradução nossa). De algum modo, esta compreensão tácita da relação entre a face exposta do tomate, os movimentos corpóreos, e o volume e a tridimensionalidade da fruta pressupõem que a aparência e a realidade do objeto sejam representadas para o sujeito enquanto tal, ou seja, como aspecto e como totalidade, conjuntamente. Isso não exigiria uma espécie de julgamento, ou, mesmo, o que Husserl (1901/1963) chama de intenções significativas? A fenomenologia da percepção (Husserl, 1901/1963, 1973/1989, 1913/2001) mostra que, no ato perceptivo, coisas aparecem, ou seja, objetos, num sentido realista, e que a descrição fenomenológica da percepção requer o rompimento dessa atitude natural, de modo que tomemos consciência do caráter subjetivo dos aspectos, ou perfis perceptivos, e da objetividade que se apresenta mediante este material sensível. Bimbenet (2015) adverte que, na percepção, esquecemos nosso perspectivismo e nos precipitamos na coisa "em detrimento das aparências que a doam" (p.76, tradução nossa). A reflexão que se faz a partir da descrição do que se vê, por mais fiel que seja à experiência perceptiva, não deixa de ser um rompimento reflexivo da experiência ingênua. Nessa medida, o senso prático, sensório-motor, tal como delineado por Noë, não pressuporia uma conjunção imprópria entre o aparente e o objetivo, calcada numa compreensão que, embora tácita, seja devedora duma espécie de olhar reflexivo? Afinal, se a reflexão não estiver sendo trazida para o seio da própria percepção, no mínimo se desenha um quadro em que uma determinada aparência significaria uma determinada totalidade objetiva, sem que esta se fizesse, de fato, presente, aqui e agora. Em outras palavras, teríamos, ao menos, uma espécie de relação entre um signo e aquilo que é designado por ele. Na descrição fenomenológica, partese do ponto em que aquilo que aparece não deve nada às aparências. A descrição de Noë, ao contrário, parece atrelar a coisa percebida à representação, ainda que não claramente expressa, das contingências sensório-motoras, exigindo uma espécie de intelecção destinada a preencher a dualidade entre 
aparência e senso de realidade. Defrontamo-nos, portanto, com o problema clássico da relação entre perceber e pensar. Qual a contribuição, afinal, das teorias praxiológicas da intencionalidade para o desenvolvimento dessa questão? Cabe perguntar, além disso, e numa perspectiva oposta à da relação entre percepção e pensamento, em que medida os paradigmas praxiológicos da percepção ultrapassam a relação instrumental entre percepção e ação?

Berthoz e Petit (2006) representam, ao seu modo, o paradigma sensóriomotor da percepção. Os autores manifestam sua proximidade com as tentativas de naturalização da fenomenologia (Petitot, Varela, Pachoud \& Roy, 1999). Nessa direção, afirmam colaborar para o estabelecimento de uma "filosofia fisiológica da ação" (Berthoz \& Petit, 2006, p.123, tradução nossa), preocupada em ancorar a teoria da cognição na ação. Para tanto, cumpre reforçar o caráter intencional da percepção. Os autores comentam: "É preciso, inicialmente, fixar o cabo de uma teoria da percepção que sublinhe firmemente a orientação cognitiva para a coisa percebida (ou para outrem) - não para o sujeito percipiente" (Berthoz \& Petit, 2006, p.123, tradução nossa).

Reeditando importantes achados da fenomenologia da percepção, notadamente husserlianos, Berthoz e Petit atrelam o inacabamento da experiência perceptiva a uma psicofisiologia da antecipação. A coisa percebida não está em mim. Encontro-me em relação contínua com coisas que não fazem parte do meu "tecido mental" (Berthoz \& Petit, 2006, p.124, tradução nossa). Trata-se de entes transcendentes. Por outro lado, tudo que percebo delas faz parte de mim; as qualidades sensíveis, as imagens visuais e impressões táteis são experiências imanentes. O perfil de um objeto exposto desde que ocupo uma determinada posição espacial corresponde a uma imagem visual. Nela, algo se dá à percepção, um objeto percebido, irredutível à minha visada parcial. As visadas parciais nos fazem esperar mais, "portam nelas uma espécie de promessa" (Berthoz \& Petit, 2006, p.125, tradução nossa). Berthoz e Petit lembram que o termo utilizado por Husserl para se referir a esta dimensão prospectiva é presunção. A presunção sobre a natureza do objeto deverá ser confirmada sempre no "ato seguinte" (Berthoz \& Petit, 2006, p.125, tradução nossa), num fluxo ininterrupto e interminável de ações perceptivas. Como Gurwitsch (1957), os autores lembram a proximidade histórica desse fluxo de consciência com as ideias de William James. Nas mais variadas circunstâncias perceptivas, "experimentamos um vazio que não é, todavia, um puro e simples nada, desde que prefigura alguma coisa, uma coisa suficientemente definida a despeito de sua ausência", atestam Berthoz e Petit (2006, p.127, tradução nossa). Segundo os autores, há literatura científica suficiente em apoio à ideia de 
uma psicofisiologia da antecipação. Freyd e Finke (1984), por exemplo, revelam que sujeitos a quem se apresentam perfis sucessivos de um objeto em movimento, como fotografias sucessivas, agem no setting experimental com forte atividade antecipadora. Freyd e Finke dizem investigar os processos dinâmicos envolvidos na representação mental de estímulos visuais estáticos, enquanto Berthoz e Petit já avançam a hipótese de uma propensão cerebral para a construção das etapas seguintes da intenção identificada de um gesto ou de um movimento.

Cabem discussões sobre o sentido internalista que interpretações neurofisiológicas da atividade perceptiva podem representar. Qual o impacto destas interpretações sobre o direcionamento das pesquisas para o caráter intencional da percepção? Rizzolatti e Sinigaglia (2008), por exemplo, sustentam uma teoria motora da percepção com base em suas pesquisas sobre a atividade cerebral. De acordo com os autores, achados recentes em neurociências, especialmente os resultados experimentais analisados por Rizzolatti, Fadiga, Gallese e Fogassi (1996), contradizem o esquema clássico que identificava no cérebro áreas específicas referentes à percepção, aos processos cognitivos de produção de intenções e de execução motora. Constatam-se, ao contrário, áreas corticais fortemente conectadas, compondo um circuito que integra informações sensoriais, intencionais e motoras sob uma base comum. Isso faz presumir a atuação do sistema motor em atividades cerebrais relativas à identificação e à localização de objetos, além das realizações motoras dirigidas a eles. Na direção do que afirmam Berthoz e Petit (2006), estas conclusões reforçam as ligações entre percepção e ação, entre a organização perceptiva e a atividade motora. Disso não decorre, contudo, que a percepção deva ser reduzida aos processos cerebrais que a sustentam. Noë e O'Regan (2002) argumentam que, embora o cérebro seja necessário para a percepção, os processos neurais não são suficientes para produzi-la. A percepção, segundo eles, é uma atividade exploratória, uma atividade baseada em habilidades (skill-based activity) de exploração ambiental. Referindo-se especificamente à visão, os autores afirmam: "Experiência visual não é algo que acontece nos indivíduos. É algo que eles fazem" (Noë \& O'Regan, 2002, p.567, tradução nossa, grifo no original).

\section{A percepção do corpo próprio}

Um paradigma sensório-motor da percepção destaca o corpo como tema privilegiado de estudos. A origem e a textura do campo perceptivo, bem como as orientações espaciais a partir das quais o identificamos, não podem ser 
compreendidas, conforme as palavras de Leder (1990), "sem referência à presença ausente do corpo percipiente" (p.13, tradução nossa). Esta constatação, conforme referência anterior, possui raízes nas investigações de Husserl e Merleau-Ponty.

Em seu "Projeto de trabalho sobre a natureza da percepção", datado de 1933, Merleau-Ponty (1996) introduz da seguinte forma suas intenções: "Pareceu-me que, no estado presente da neurologia, da psicologia experimental (particularmente da psicopatologia) e da filosofia, seria útil retomar o problema da percepção e particularmente da percepção do corpo próprio" (p.11, tradução nossa). É marcante o fato do filósofo estabelecer seu problema como o da percepção do corpo próprio, formulação que se desdobra nas ideias, distintas e conexas, de que o corpo figura como o sujeito da percepção e de que o corpo próprio pode tornar-se um dos elementos centrais do campo perceptivo. Perceber envolve nossa condição situada em algum ponto do espaço, e a possibilidade que temos de contornar as coisas e de explorá-las. Nessa medida, o corpo é caracterizado por Merleau-Ponty (1945) como "pivô do mundo" (p.97, tradução nossa). Tudo que se destaca como objeto da nossa atenção apresentase não apenas sob o horizonte do espaço exterior, mas igualmente sobre um fundo de atividade corpórea. Merleau-Ponty, ocupado em desenvolver filosoficamente tanto a estrutura de objeto e horizonte quanto a relação gestáltica entre figura e fundo, e considerando o fundo perceptivo como o contexto não necessariamente reconhecido da percepção, salienta a natureza impercebida da corporeidade. Em suas palavras, o espaço corporal é "o termo não-percebido para o qual todos os objetos voltam sua face" (Merleau-Ponty, 1945, p.97, tradução nossa), "a obscuridade da sala necessária à claridade do espetáculo" (Merleau-Ponty, 1945, p.117, tradução nossa). Segundo o filósofo, é o funcionamento sinérgico e anônimo do corpo que sustenta nossa "inerência a um mundo" (Merleau-Ponty, 1945, p.97, tradução nossa). Merleau-Ponty encontra na noção de esquema corporal, destacada pela literatura psicopatológica do seu tempo, a oportunidade de avançar na investigação sobre o papel do corpo na percepção. Ao mesmo tempo, o filósofo discute, a partir de estudos sobre a aquisição da imagem corporal na infância, o papel da visibilidade do corpo na estruturação do espaço percebido (Merleau-Ponty, 1951/1997, 2001).

Gallagher (2005), tendo por fundamento teórico a fenomenologia de Husserl e de Merleau-Ponty, e com base em aportes da literatura psicológica contemporânea, relança o problema acerca da estrutura da consciência perceptiva em referência à corporalidade, ou ao que chama de embodiment. 
Duas questões orientam sua pesquisa: "Em que medida, e precisamente de que modo, o corpo de alguém aparece como parte do seu campo perceptual? Em que medida, e precisamente de que modo, o corpo de alguém restringe ou molda o campo perceptual? " (Gallagher, 2005, p.17, tradução nossa). Nota-se que elas correspondem ao significado duplo do problema merleau-pontiano da percepção do corpo próprio. Elas têm correlação, igualmente, com os conceitos psicológicos de imagem corporal e de esquema corporal. De acordo com Gallagher, a despeito da ambiguidade e da confusão observadas no uso histórico desses dois termos, eles são úteis ao desenvolvimento daquelas duas perguntas ${ }^{1}$. O conceito de imagem corporal pode auxiliar-nos a entender como se dá a manifestação do corpo próprio no campo perceptual, enquanto o de esquema corporal pode ser proveitoso na resposta ao problema do papel que o corpo exerce na configuração do campo perceptual. Para Gallagher, a clarificação destes conceitos pode prover condições para o avanço da compreensão do papel que a corporalidade (embodiment) possui na estruturação da consciência e na constituição da cognição.

Gallagher (2005) define imagem corporal da seguinte forma: "A imagem corporal consiste em um complexo conjunto de estados intencionais e disposições - percepções, crenças e atitudes - no qual o objeto intencional é o próprio corpo de alguém" (p.25, tradução nossa). A imagem corporal diz respeito, portanto, a uma intencionalidade referida ao self, ou ao corpo do self. Segundo o autor, estudos contemporâneos sobre a imagem corporal centrados na anorexia e na obesidade permitem que se identifiquem três tipos de conteúdos intencionais referentes ao corpo próprio: o corpo como percepto, e que diz respeito à experiência perceptiva do sujeito em relação ao próprio corpo; o conceito corporal, que se relaciona à compreensão conceitual sobre o próprio corpo, e que envolve conhecimentos do senso comum e científicos; e o afeto corporal, que concerne à atitude emocional do sujeito em relação ao próprio corpo. Embora o conceito corporal e o afeto corporal não se manifestem comumente nos termos de um reconhecimento consciente (conscious awareness), eles integram um conjunto intencional dirigido ao corpo próprio.

Este último detalhe é importante na medida em que o esquema corporal, em contrapartida, refere-se a "um sistema de funções sensório-motoras que operam abaixo do nível da intencionalidade referida ao eu [self]" (Gallagher, 2005, p.26, tradução nossa). Trata-se, de acordo com Gallagher, de um conjunto

\footnotetext{
${ }^{1}$ Gallagher (2005) destaca, inclusive, o fato da versão inglesa da Fenomenologia da percepção, principal obra de Merleau-Ponty, indicar como tradução de "schéma corporel" a expressão "body image".
} 
de performances tácitas, subpessoais, e que possui um papel dinâmico na organização da postura corporal e na condução dos movimentos. Nessa medida, nossa movimentação no mundo, na maior parte do tempo, pode abdicar do corpo como percepto. O "corpo-em-ação", comenta Gallagher (2005), "tende a apagarse na maioria das suas atividades propositadas" (p.26, tradução nossa).

Um dos benefícios da distinção conceitual entre imagem e esquema corporal é a possibilidade de constatar e de investigar a interação entre estes dois níveis de atividade perceptiva. Gallagher (2005) comenta, sobretudo, evidências empíricas acerca da interferência das performances corporais relativas ao esquema corporal sobre a percepção do próprio corpo, bem como na percepção do espaço e dos objetos. Pesquisas, analisadas pelo autor, indicam que a prática de exercícios, de dança e outras atividades que afetam a motilidade e o esquema postural tem potencial para modificar positivamente a avaliação das pessoas acerca da sua imagem corporal. Outros trabalhos mostram que experiências locomotoras nas crianças, especialmente 0 ato de engatinhar, facilitam 0 desenvolvimento do esquema corporal, e possuem importante papel no progresso tanto da atenção visual a mudanças no ambiente quanto de estratégias perceptuais para a procura de objetos. Os estudos sugerem, de modo geral, que os ajustamentos do esquema corporal, que permanecem num plano de fundo perceptual, aumentam a capacidade de atenção aos estímulos externos.

As pesquisas de Gallagher (2005) reforçam o que Gennart (2011), num registro mais filosófico, chama de "porosidade do corpo de carne" (p.140, tradução nossa). Longe de representar uma figura orgânica individual, fechada em si mesma, as impressões peculiares ao corpo "prolongam-se espontaneamente 'para fora'" (Gennart, 2011, p.139, tradução nossa). É próprio da nossa presença carnal eclodir, gerando um espaço de "intimidade recíproca" (Gennart, 2011, p.139, tradução nossa) com as coisas. O esquema corporal não se desenvolve sem impressões sensíveis, ao passo que estas não possuem forma sem um esquema pré-conceitual que propague "os traços estruturais da "os traços estruturais da sua vivacidade" (Gennart, 2011, p.141, tradução nossa). A corporalidade é, portanto, um aspecto central da percepção, e reforça a dimensão da nossa participação com as coisas que as teorias praxiológicas da intencionalidade buscam descrever atentamente. A literatura voltada à corporalidade, especialmente às noções de esquema e de imagem corporal, mostra os índices dessa dimensão de participação. 


\section{Percepção e ação conjuntas}

A ideia de participação remete ainda mais diretamente à nossa presença conjunta, ou partilhada, no mundo. É apenas ao custo de um processo de abstração que se pode discutir a percepção humana como ação de sujeitos individuais sobre objetos contextualizados apenas fisicamente. Toda percepção se dá como atividade de sujeitos sociais, em um mundo socialmente contextualizado. A literatura filosófica e científica aborda o tema destacando duas perspectivas distintas e interdependentes: a percepção do outro e o contexto social de percepção das coisas. A dimensão social da percepção reforça a tendência enativa, ou praxiológica, de estudo da intencionalidade perceptiva. É o que se depreende de elaborações teóricas em torno dos programas de pesquisa voltados à cognição social, mais especificamente ao fenômeno da atenção conjunta, e às bases neurais da empatia, campo em que se destacam os estudos sobre os chamados neurônios espelho.

Sartre (1943/1980), ao dedicar-se à análise e crítica da concepção de Husserl acerca da intersubjetividade, afirma: "para Husserl, o mundo tal como se apresenta à consciência é intermonádico" (p.278, tradução nossa). O outro possui não apenas uma manifestação concreta e empírica, mas figura como condição da unidade e da riqueza do mundo percebido. Sozinho ou acompanhado, ao me voltar a um objeto qualquer, por exemplo, uma mesa, tem-se pressuposto o outro como "camada de significações constitutivas que pertencem ao próprio objeto que considero", escreve Sartre (1943/1980, p.278, tradução nossa). Em outras palavras, outrem participa como fiador da objetividade da coisa percebida. Sartre refere-se à questão da percepção por perfis (Abschattungen), destacada pelas descrições husserlianas da intencionalidade perceptiva (Husserl, 1973/1989; 1913/2001). As coisas apresentam-se a nós sempre de uma perspectiva ou de outra, de modo que se manifestam objetivamente mediante uma série de perfis ausentes cointencionados. A manifestação dos horizontes perceptivos remete, sobretudo, à coexistência dos perfis a cada momento da presentação perceptiva. É insuficiente, todavia, caracterizar a manifestação daqueles perfis perceptivos que não adquirem exposição num dado momento como correlatos de exposições possíveis para si. Conforme Gallagher e Zahavi (2008), que analisam as posições de Husserl e Sartre sobre o tema, aqueles perfis devem ser o correlato de percepções possíveis no quadro de uma pluralidade de sujeitos, ou seja, numa dimensão essencialmente intersubjetiva. Essa constatação é suficiente para alçar o outro a "objeto privilegiado" (Sartre, 1943/1980, p.300, tradução nossa). 
Não aplicamos a outrem as categorias utilizadas para organizar as coisas tempo-espaciais. Podemos dizer que alguém se encontra ao lado da cama, ou a tantos metros de uma árvore, percebemos, contudo, que a árvore é ligada a outrem numa relação que transcende a distância. Desdobra-se, nessa relação, "uma espacialidade que não é minha espacialidade" (Sartre, 1943/1980, p.300, tradução nossa, grifo no original), "uma orientação que me foge", afirma Sartre (p.300, tradução nossa, grifo no original). Pode-se dizer que a relação de outrem com as coisas e mesmo conosco é um objeto de conhecimento, na medida em que preserva um caráter de probabilidade. É provável que o sujeito veja a árvore, mas ele pode estar absorto em pensamentos de outra ordem, ou pode até ser cego. No entanto, a relação de outrem com aquilo que o cerca nos é "dada inteira" (Sartre, 1943/1980, p.300, tradução nossa), quer dizer, ela está no mundo como algo que podemos conhecer e que nos escapa inteiramente. 0 resultado, escreve Sartre (1943/1980), é uma "descentração do mundo" (p.301, tradução nossa). A aparição de alguém instala um plano de fundo das coisas "que me escapa por princípio e que lhes é conferida de fora" (Sartre, 1943/1980, p.301, tradução nossa). O objeto percebido volta para outrem uma face que me escapa. A relação da árvore com outro sujeito é percebida como vinculação objetiva, mas não posso captar o verde da árvore da forma como ele aparece a outrem. Ao mesmo tempo em que tudo existe para mim, tudo é percorrido por uma "fuga invisível" (Sartre, 1943/1980, p.301, tradução nossa) na direção do outro.

Parte expressiva dos estudos da intersubjetividade nas ciências cognitivas é dedicada ao problema da espacialidade. Berthoz (2004), por exemplo, propõe a "espacialização da empatia" (p.273, tradução nossa), não no sentido de reduzir o problema da relação com outrem a uma questão geométrica, mas com base na consideração de que "mudar de ponto de vista é mudar de referencial, quer dizer, resolver um problema espacial" (p.254-255, tradução nossa). Segundo o autor, os fundamentos da tese da espacialização da empatia esclarecem-se mediante o estudo do desenvolvimento infantil. É o que mostram, com efeito, as pesquisas norteadas pelo conceito de atenção conjunta.

A atenção conjunta é o eixo nocional de pesquisas interdisciplinares voltadas à investigação das origens da cognição humana, sobretudo a linguagem e a compreensão social (Meltzoff, Kuhl, Movella \& Sejnowski, 2009). Na psicologia do desenvolvimento, âmbito em que o conceito foi concebido, a atenção conjunta faz referência a habilidades sociais, por parte das crianças, nos planos da percepção e da ação, principalmente à passagem, em torno do nono e do décimo segundo mês de vida, da ocupação diádica por parte dos bebês, ora 
com coisas, eventos ou situações, ora com outra pessoa, à partilha do seu objeto de interesse com outrem num esquema triádico. Moll e Meltzoff (2011) caracterizam a atenção conjunta como atos, por parte do bebê, de focar naquilo que prende a atenção de outrem, acompanhando seu olhar ou suas indicações gestuais, e mais tarde, de apontar ou mostrar coisas para outros.

Um primeiro afluxo de estudos em torno da atenção conjunta fundamenta sua linha de pesquisa na teoria da mente. Trata-se, nessa medida, de investigar o momento inicial da compreensão, por parte da criança, de outrem como agente intencional da mesma forma que ela própria (Carpenter, Nagell \& Tomasello, 1998; Tomasello, 1999). Para Bimbenet (2011a), os pressupostos dessas pesquisas denotam uma inclinação intelectualista. Tomasello (1999), por exemplo, vê no comportamento dos bebês elementos que fortalecem uma teoria da simulação. Segundo o autor, a ideia de que simulo "o funcionamento psicológico de outras pessoas por analogia com o meu próprio, conhecido mais direta e intimamente por mim" (Tomasello, 1999, p.71, tradução nossa) poderia explicar os acontecimentos referidos na ideia de atenção conjunta. Os comportamentos infantis de atenção conjunta, como olhar alternadamente para objetos e para seus parceiros adultos, sugerem, com efeito, a inclusão do outro na referência a uma coisa qualquer. Esta última passa a ser o objeto de uma visada comum, de modo que a relação à coisa ou ao mundo é incorporada em um contexto social. A questão que se impõe a partir desses estudos, segundo Bimbenet (2011a), é como não intelectualizar o fato de que temos a experiência do mundo, e não de "um mundo subjetivo-relativo" (p.92, tradução nossa).

A lógica da teoria da mente vertida ao campo da percepção infantil do espaço resulta na compreensão da multiplicidade perspectiva como produto de atos inferenciais, por parte da criança, acerca do que seria visto por ela caso estivesse no lugar do seu congênere. É o que se depreende de estudos acerca da perspectiva visual na infância (Masangkay e outros, 1974; Moll \& Tomasello, 2006; Moll \& Meltzoff, 2011), que delimitam seu escopo de trabalho como investigações sobre o "desenvolvimento precoce da inferência perceptiva visual" (Masangkay e outros, 1974, p.366, tradução nossa). Esse gênero de estudos tem como referência as pesquisas de Piaget e Inhelder (1948) sobre a representação do espaço na infância baseadas em experimentos sobre a organização relativa das perspectivas.

Berthoz (2004), baseando-se, igualmente, em Piaget e Inhelder (1948), chega a conclusões diferentes acerca da evolução da experiência do espaço. De acordo com o autor, o que distingue sua abordagem do problema em relação àqueles que acentuam uma teoria da mente é a reintegração do "corpo sensível 
e agente no mecanismo, de sorte que não se trata mais de uma teoria, mas de uma verdadeira vivência por mim do ponto de vista do outro" (Berthoz, 2004, p.261-262, tradução nossa). Berthoz mostra que, no trabalho de Piaget e Inhelder, o fator comum entre a atividade perceptiva do início da vida humana e as construções representativas que emergem por volta do sétimo ano da criança repousa na motricidade. A vivência motriz do espaço não é, contudo, experimentada solitariamente. Pode emergir, então, uma teoria da atenção conjunta, ou da ação conjunta, com base na motricidade. O esboço dessa teoria é mais claramente apresentado por Berthoz em seu trabalho conjunto com Petit (Berthoz \& Petit, 2006). Os autores argumentam pela fundação da relação com outrem na empatia com as suas ações, na identificação calcada na estruturação ativa do mundo e no reconhecimento do outro como ente "capaz de". Berthoz e Petit reconhecem o teor teórico da formulação, que deveria ser, segundo eles, reforçada por trabalhos empíricos.

O fortalecimento desse ponto de vista advém, por exemplo, de estudos em que a atenção conjunta é apresentada como processo baseado numa "intersubjetividade primária". Observa-se que recém-nascidos são capazes de coordenar iniciativas posturais, movimentos faciais e de membros superiores às características dinâmicas dos movimentos intencionais dos adultos (Trevarthen, 2011). Essas capacidades denotam um modo de interação independente das mentalizações inferenciais exigidas pela teoria da mente, e reforçam a ideia de que as crianças são capazes de perceber diretamente as pessoas como agentes mediante seus movimentos corporais (Gallagher \& Zahavi, 2008).

Pesquisas sobre as bases neurais da imitação e da compreensão das ações de outrem dão, igualmente, sustentação empírica à ideia de ação conjunta. Já nos referimos à teoria motora da percepção sustentada por Rizzolatti e Sinigaglia (2008) a partir de seus trabalhos sobre a atividade cerebral. O tema específico das pesquisas lideradas por Rizzolatti é a compreensão de ações motoras. No início da década de 1990, experimentos com macacos indicaram a existência de neurônios, batizados de neurônios espelho (mirror neurons), que recebiam descargas não apenas quando os animais executavam movimentos de preensão, mas igualmente quando viam os experimentadores realizarem movimentos intencionais com as mãos. Conforme Rizzolatti e outros (1996), essa descoberta implica a identificação, no plano do sistema neuronal motor, de uma relação entre movimentos efetivamente observados e movimentos efetivamente realizados. Trata-se, de acordo com os pesquisadores, de um sistema combinatório de observação e de execução (observation/execution matching system). Ações motoras observadas pelos macacos encontram "representação" 
na atividade neuronal, mesmo que elas não sejam executadas pelos animais. Um pouco mais tarde, revelou-se a existência de um sistema-espelho no homem (Berthoz \& Petit, 2006).

Rizzolatti e Sinigaglia (2008) comentam três importantes aspectos dos neurônios espelho. Primeiramente, não se trata simplesmente de tematizar o reconhecimento mútuo de experiências motoras, mas de atos mediante os quais as coisas que nos cercam adquirem significado. Estabelece-se, portanto, uma relação intrínseca entre ação e compreensão pré-conceitual e pré-linguística. Além disso, evidencia-se como o reconhecimento do outro e das suas ações depende do nosso patrimônio motor. Por fim, a descoberta do sistema de neurônios espelho delineia um quadro teórico e experimental para o estudo de diversas outras manifestações da nossa experiência comum, como a imitação, a aprendizagem, a comunicação verbal e a experiência emocional.

Berthoz e Petit (2006) apoiam-se na teoria dos neurônios espelho para se contrapor ao pressuposto de que atos inferenciais são a condição necessária para o reconhecimento de outrem. Advertem, por outro lado, para o risco de uma extrapolação acrítica dos elementos referentes à pesquisa neurocientífica. Voltamos aos argumentos de Noë e O'Regan (2002), que definem a percepção como um acontecimento no mundo, e não no interior do sujeito perceptivo. Já Bimbenet (2011b) destaca a importância de se refletir, não somente a partir dos achados sobre o sistema-espelho, mas também da atenção conjunta, sobre a origem corporal da linguagem. Não seria esse um caminho para se compreender melhor o caráter propriamente cognitivo da percepção e da ação, sem isolá-los do âmbito da abstração e da categorização?

\section{Considerações finais}

Realizamos, em suma, um trabalho de reconhecimento e de análise de pesquisas correspondentes ao delineamento de um campo de investigações centrado em teorias praxiológicas da percepção. Identificamos linhas de estudo e seus fundamentos, redes e controvérsias conceituais presentes em aportes contemporâneos advindos da psicologia, das neurociências cognitivas, da filosofia da mente e da fenomenologia. Tomamos como pressuposto a concentricidade entre a experiência do espaço, do corpo próprio e de outrem. Vimos que a literatura acerca de cada um desses planos de experiência perceptiva provê material para a análise de temas de pesquisa e de questões conceituais relativas ao caráter sensório-motor da percepção. Demos destaque aos problemas da atenção perceptual e da percepção amodal, do esquema e da imagem corporal, 
da atenção conjunta e dos neurônios espelho, tópicos relevantes no campo de pesquisa em apreço, mas que estão longe de esgotar a rede conceitual que o caracteriza. No que concerne à atenção e à percepção amodal, sobressai da análise a orientação da atividade perceptual para o mundo percebido, o que implica não apenas a exploração do espaço, com seus detalhes, pelo sujeito, como pressupõe uma experiência sensível que abarca inclusive os aspectos impercebidos dos territórios de percepção. O caráter intencional e ativo da percepção é reforçado pelo exame dos conceitos de esquema e de imagem corporal. O corpo ativo apaga-se em prol das suas atividades no mundo e dispõe-se em intimidade com as coisas. E quando o próprio corpo se destaca como objeto de percepção, é ainda em circuito com a vivência do espaço e do tecido social que ele se mostra. Na atenção conjunta e nas questões relativas aos neurônios espelho, a porosidade do percipiente em relação ao outro ganha destaque, levantando-se a questão do quanto nossa experiência do espaço é conjugada ao outro por incorporação, ou seja, por sensibilidade corpórea à sua perspectiva.

De modo geral, o arranjo aqui proposto, que abrange a experiência do espaço, do corpo próprio e de outrem, pode contribuir para a compreensão dos debates em torno da relação entre percepção e ação, e principalmente, para o amadurecimento de uma concepção de subjetividade encarnada, viva e móvel. A ideia internalista de sujeito, própria da cultura moderna, vem sendo sobrepujada pela concepção do sujeito situado em termos espaciais, temporais, sociais e históricos. Debates em torno da espacialidade, da corporeidade e da intersubjetividade substanciam este processo.

Estudos vindouros no campo específico de pesquisas circunscrito em nosso trabalho poderão centrar-se: na discussão aprofundada dos três eixos de investigação a partir do exame minucioso de problemas de pesquisa e conceitos de destaque em cada um deles; na articulação dos problemas referentes aos três eixos, como a tematização, por exemplo, do caráter amodal do corpo próprio, ou na relação entre o esquema corporal, a imagem corporal e a intersubjetividade; no delineamento dos principais elementos históricos referentes à constituição das teorias praxiológicas da percepção, destacando as especificidades relativas aos três planos temáticos da pesquisa; e, finalmente, no desenvolvimento de discussões sobre a relação entre a percepção e outros processos cognitivos básicos, como a imaginação e a memória, a partir das teorias praxiológicas da intencionalidade perceptiva. 


\section{Referências}

Barbaras, R. (2006). Préface. Em G. Simondon. Cours sur la perception (pp.IXXVI). Paris: PUF.

Berthoz, A. (2004). Physiologie du changement de point de vue. Em A. Berthoz \& G. Jorland. L'empathie (pp.251-275). Paris: Odile Jacob.

Berthoz, A. \& Petit, J-L. (2006). Phénoménologie et physiologie de l'action. Paris: Odile Jacob.

Bimbenet, E. (2011a). L'animal que je ne suis plus. Paris: Gallimard.

Bimbenet, E. (2011b). Après Merleau-Ponty: études sur la fécondité d'une pensée. Paris: Vrin.

Bimbenet, E. (2015). L'invention du réalisme. Paris: Les Éditions du Cerf.

Briscoe, R. \& Grusch, R. (2015). Action-based theories of perception. The Stanford Encyclopedia of Philosophy. Recuperado em 7 de dezembro, 2015, de http://plato.stanford.edu/archives/fall2015/entries/actionperception/.

Carpenter, M., Nagell, K. \& Tomasello, M. (1998). Social cognition, joint attention and communicative competence from 9 to 15 months of age. Monographs of the Society for Research in Child Development, 63(4), 1-142. Recuperado em 7 de abril, 2021, de www.jstor.org/stable/1166214.

Freyd, J. \& Finke, R. (1984). Representational momentum. Journal of Experimental Psychology: Learning, Memory, and Cognition, 10(1), 126132. Recuperado em 7 de abril, 2021, de https://psycnet.apa.org/record/1984-16934-001.

Gallagher, S. (2005). How the body shapes the mind. Oxford/ New York: Oxford University Press.

Gallagher, S. \& Zahavi, D. (2008). The phenomenological mind: an introduction to philosophy of mind and cognitive science. London/ New York: Routledge.

Gennart, M. (2011). Corporeité et présence: jalons pour une approche du corps dans la psychose. Argenteuil: Le Cercle Herméneutique.

Gurwitsch, A. (1957). Théorie du champ de la conscience. Bruges: Desclée de Brouwer. 
Husserl, E. (1963). Recherches logiques: éléments d'une élucidation phénoménologique de la connaissance (Vol.3) Paris: PUF. (Original publicado em 1901).

Husserl. E. (1989). Chose et espace: leçons de 1907 (J.-F. Lavigne, trad.). Paris: PUF. (Original publicado em 1973).

Husserl, E. (2001). Idées directrices pour une phénoménologie et une philosophie phénoménologique pures (P. Ricoeur, trad.). Paris: Gallimard. (Original publicado em 1913).

Kelly, S. (2008). Content and constancy: phenomenology, psychology, and the content of perception. Philosophy and Phenomenological Research, 76(3), 682-690. Recuperado em 7 de abril, 2021, de https://www.jstor.org/stable/40041205.

Leder, D. (1990). The absent body. Chicago/ Londres: The University of Chicago Press.

Mack, A. (2003). Inattentional blindness: looking without seeing. Current Directions in Psychological Science, 12(5), 180-184. Recuperado em 7 de abril, 2021, de https://journals.sagepub.com/doi/10.1111/1467$\underline{8721.01256 .}$.

Masangkay, Z., McCluskey, K., McIntyre, C., Sims-Knight, J., Vaughn, B. \& Flavell, J. (1974). The early development of inferences about the visual percepts of others. Child Development, 45(2), 357-366. Recuperado em 7 de abril, 2021, de https://journals.sagepub.com/doi/10.1111/14678721.01256.

Meltzoff, A., Kuhl, P., Movella, J. \& Sejnowski, T. (2009). Foundations for a new science of learning. Science, 325, 284-288. Recuperado em 7 de abril, 2021, de https://science.sciencemag.org/content/325/5938/284.long.

Merleau-Ponty, M. (1945). Phénoménologie de la perception. Paris: Gallimard.

Merleau-Ponty, M. (1996). Le primat de la perception et ses conséquences philosophiques. Lagrasse: Verdier.

Merleau-Ponty, M. (1997). Les relations avec autrui chez I'enfant. Em M. Merleau-Ponty, Parcours: 1935-1951 (pp.147-229). Lagrasse: Verdier (Original publicado em 1951).

Merleau-Ponty, M. (2001). Psychologie et pédagogie de l'enfant: cours de Sorbonne 1949-1952. Lagrasse: Verdier.

Michotte, A. (1955). Perception et cognition. Acta Psychologica, 11, 70-91. 
Michotte, A., Thinès, G., \& Crabbé, G. (1964). Les compléments amodaux des structures perceptives. Louvain/Paris: Publications Universitaires de Louvain, Éditions Béatrice-Nauwelaerts.

Moll, H. \& Meltzoff, A. (2011). Joint attention as the fundamental basis of understanding perspectives. Em A. Seemann (Ed.). Joint Attention: new developments in psychology, philosophy of mind, and social neuroscience (pp.393-413). Massachusetts: MIT Press.

Moll, H. \& Tomasello, M. (2006). Level I perspective-taking at 24 months of age. British Journal of Developmental Psychology, 24, 603-613. Recuperado em 7 de abril, 2021, de https://bpspsychub.onlinelibrary.wiley.com/doi/abs/10.1348/026151005X 55370.

Noë, A. (2004). Action in perception. Cambridge/London: The MIT Press.

Noë, A. (2012). Varieties of presence. Cambridge (Mass.)/London: Harvard University Press.

Noë, A. \& O'Regan, K. (2002). On the brain-basis of visual consciousness: a sensorimotor account. Em A. Noë \& E. Thompson (orgs.). Vision and mind: selected readings in the philosophy of perception (pp.567-598). Cambridge/London: The MIT Press.

Noë, A. \& Thompson, E. (2002). Introduction. Em A. Noë \& E. Thompson (Eds.). Vision and mind: selected readings in the philosophy of perception (pp.0114). Cambridge/London: The MIT Press.

Petitot, J., Varela, F., Pachoud, B. \& Roy, J-M. (Eds.). (1999). Naturalizing phenomenology: issues in contemporary phenomenology and cognitive science. Stanford: Stanford California Press.

Piaget, J. \& Inhelder, B. (1948). La représentation de l'espace chez l'enfant. Paris: PUF.

Rensink, R., O'Regan, J. \& J. Clark (1997). To see or not to see: the need for attention to perceive changes in scenes. Psychological Science, 8(5), 368373. Recuperado em 7 de abril, 2021, de https://journals.sagepub.com/doi/10.1111/j.1467-9280.1997.tb00427.x.

Rizzolatti, G., Fadiga, L., Gallese, V. \& Fogassi, L. (1996). Premotor cortex and the recognition of motor actions. Cognitive Brain Research, 3, 131-141. Recuperado em 7 de abil, 2021, de https://www.sciencedirect.com/science/article/abs/pii/0926641095000380 
Rizzolatti, G. \& Sinigaglia, C. (2008). Les neurons miroirs (M. Raiola, Trad.). Paris: Odile Jacob.

Sartre, J-P. (1980). L'être et le néant: essai d'ontologie phénoménologique. Paris: Gallimard. (Original publicado em 1943).

Sévérac, P. (2004). La perception. Paris: Ellipses.

Simons, D. \& Chabris, C. (1999). Gorillas in our midst: sustained inattentional blindness for dynamic events. Perception, 28(9), 1059-1074. Recuperado em 7 de abril, 2021, de https://journals.sagepub.com/doi/10.1068/p281059.

Simons, D. \& Levin, D. (1997). Change blindness. Trends in Cognitive Sciences, 1(7), 261-267. Recuperado em 7 de abril, 2021, de https://www.cell.com/trends/cognitive-sciences/fulltext/S13646613(97)01080-2.

Tomasello, M. (1999). The cultural origins of human cognition. Cambridge: MIT Press.

Trevarthen, C. (2011). The generation of human meaning: how shared experience grows in infancy. Em A. Seemann (Org.). Joint Attention: new developments in psychology, philosophy of mind, and social neuroscience (pp.73-113). Massachusetts: MIT Press.

Tse, P. (1999). Volume completion. Cognitive Psychology, 39, 37-68. Recuperado em 7 de abril, 2021, de https://www.sciencedirect.com/science/article/abs/pii/S001002859990715 $\underline{6}$.

Van Lier, R. \& Gerbino, W. (s/d). Perceptual completions. [Texto da internet]. Recuperado em 27 de abril, 2021, de http://gestaltrevision.be/pdfs/oxford/van Lier\&GerbinoPerceptual completions.pdf.

Varela, F., Thompson, E. \& Rosch, E. (1993). The embodied mind: cognitive science and human experience. Cambridge (Mass.)/London: MIT Press.

Wagemans, J., Kubovy, M., Peterson, M.; Elder, J., Palmer, S. \& Singh, M. (2012). A century of Gestalt Psychology in visual perception: I. Perceptual grouping and figure-ground organization. Psychological Bulletin, 138(6), 1172-1217. Recuperado em 7 de abril, 2021, de https://doi. apa.org/doiLanding?doi=10.1037\%2Fa0029333. 
Wagemans, J., Van Lier, R. \& Scholl, B. (2006). Introduction to Michotte's heritage in perception and cognition research. Acta Psychologica, 123, 119. Recuperado em 7 de abril, de https://www.sciencedirect.com/science/article/abs/pii/S000169180600075 8?via\%3Dihub.

\section{Nota sobre o autor:}

Danilo Saretta Verissimo é Professor-Associado Livre-docente do Departamento de Psicologia Social da Faculdade de Ciências e Letras - UNESP Campus Assis. E-mail: danilo.verissimo@gmail.com.

Data de submissão: 09.04.2020

Data de aceite: 09.03.2021 